\title{
A Study on Spread Effect and Induction Effect of High-tech Services in China
}

\author{
Liu Haitao ${ }^{1, a}$, Wang Yangang ${ }^{2, b^{*}}$ \\ ${ }^{1}$ Hebei university of science and\& technology, \\ China,Shijiazhuang,Postcode:050018 \\ ${ }^{2}$ College of Economics \& Management, Hebei university of science and\& technology, \\ China,Shijiazhuang,Postcode:050018 \\ aliu_lht@163.com, bwangyangang1019@163.com
}

\section{Keywords: High-tech Services; Spread Effect; Induction Effect}

Abstract. As the research object to high-tech services, the paper through the integration and analysis of the input-output table finds that the spread effects of high-tech services is less than the manufacturing and infrastructure at present stage, and the growth of production of high-tech services is mainly associated with the increase of consumption. Moreover,Manufacturing is the largest affected as output and price of high-tech services change.

\section{Introduction}

Currently, the academic research focuses almost entirely on the status and countermeasure, industrial characteristics and the evaluation index of the high-tech services and so on ${ }^{[1]}$. Moreover, the national economy demanding for high-tech services also shows an increasing trend. As currently envisaged, however, the academic is lack of the research of the national economy status and the influence of high-tech services, and mechanism of interaction between high-tech services and other industries; On the other hand, high-tech services is still in early phases of development in china, which has many prominent problems. So how to promote its rapid development and optimization of its industrial structure is the problems which we need to be addressed. Given that, the paper uses spread effect and induction effect to explore the correlation between high-tech services and other industries, and its status and influence in the national economy on the basis of China's input-output statistics yearbook in $2010^{[2]}$.

\section{Establish high-tech services input-output table}

Input-output Analysis ${ }^{[3]}$ mainly uses output table to quantification-ally analyze economic problems, proposed by an American economist, Wassily Leontief for the first time in 1936. Input-output table is a checker-board sheets composed of the sources of inputs and the place of consumption in the national economic for a certain period, which explains the interrelated quantity relations among economy and technology of all departments.

In general, input-output table focuses on interior industries in industry segments. The paper highly integrates China's input-output statistics yearbook in 2010 based on its characteristics, and quantity relation between high-tech services and other industries. High-tech services as an important component of the tertiary industry is difficult to accurately reflected.So high-tech services as an independent research department is spun off from the tertiary industry, which mainly includes information transmission, computer service and software, financial inter-mediation, business services, scientific research and technical services. At the same time, the high-tech services which is a modern services with the high and new technology industry combination of,must be a close relationship with other services. So the another services except high-tech services is known as the traditional services to study the relationship among the high -tech services and another services.

Chinese accelerated development of industrialization increases the demand of high-tech services, but the development of industrialization is reflected in the rapid development of China's 
manufacturing industry. And high-tech services and manufacturing has the promoting relations each other objectively. So manufacturing is separated from industry to study the relationship with high-tech services. Besides, mining, production and supply of electricity, gas and water, construction which can be referred to as infrastructure provide a general material conditions for social production and living, such as railway, highway, water and electricity gas etc.

Agriculture is the foundation of the national economy, which provides important raw materials and the broad market for the development of industry and services. At the same time, the development of the services enhances the staying power of agricultural production, and promotes the others' socialization and specialization. Therefore, farming, forestry, animal husbandry and fishery are called agricultural to research.In conclusion, the paper constructs the highly integrated input-output profiles with China's high-technology services of five department including agriculture, infrastructure, manufacturing, traditional services and high-tech services.

In conclusion, the paper constructs the highly integrated input-output profiles with China's high-technology services of five department including agriculture, infrastructure, manufacturing, traditional services and high-tech services.

\section{Analytics of the correlation effect of the high-tech services}

Analytics of the spread effect. In national economic system, an industry has hold two opposed ability to influence on other industries and induct the influence of other industries. And Industrial spread effect includes pulling-effect with influence coefficient $\left({ }^{\lambda_{j}}\right)$ expressed and propulsive effect with response coefficient $\left({ }^{\delta_{i}}\right)$ measured. So the paper uses the influence coefficient and response coefficient to illustrate it.

The formula of the influence coefficient and response coefficient is shown as the following:

$$
\lambda_{j}=\frac{\sum_{i=1}^{n} \bar{b}_{i j}}{\frac{1}{n} \sum_{j=1}^{n} \sum_{i=1}^{n} \bar{b}_{i j}}(j=1,2, \mathrm{~L}, n) \quad(1), \quad \delta_{i}=\frac{\sum_{j=1}^{n} \bar{b}_{i j}}{\frac{1}{n} \sum_{i=1}^{n} \sum_{j=1}^{n} \bar{b}_{i j}}(i=1,2, \mathrm{~L}, n)
$$

$\lambda_{j}$ means the influence coefficient of $j$ th sector, and ${ }{ }_{i}$ says the response coefficient of ith industry, and $\bar{b}_{i j}$ expresses the coefficient of leontief inverse.

Table 1, The influence coefficient and response coefficient of five sectors

\begin{tabular}{ccc}
\hline & $\begin{array}{c}\text { influence } \\
\text { coefficient }\end{array}$ & $\begin{array}{c}\text { response } \\
\text { coefficient }\end{array}$ \\
\hline agriculture & 0.80173 & 0.58287 \\
infrastructure & 1.17859 & 0.76666 \\
manufacturing & 1.32730 & 2.28825 \\
traditional services & 0.83768 & 0.75727 \\
high-tech services & $\mathbf{0 . 8 5 4 6 9}$ & $\mathbf{0 . 6 0 4 9 5}$ \\
\hline
\end{tabular}

In table 1 , the influence coefficient of high-tech services is higher than the traditional services, so high-tech services is given priority to in the process of development of services. Moreover,its industry characteristics determines that its influence coefficient and response coefficient are lower than the manufacturing and infrastructure. On the other hand, it shows that china is still in the middle stage of infrastructure driving and industrialization.Response coefficient of high-tech services is basically flat with agriculture, infrastructure and traditional services, which indicates that high-tech services plays an important role in the national economy development and other industry production. 
From the above, spread effect of high-technology services is not as good as the manufacturing and infrastructure,but compared with the traditional services and agriculture, its pulling-effect and propulsive effect is more obvious .

Analytics of inducing effect. Influence coefficient and response coefficient, to some extent, show the pulling effect and propulsive effect of all departments, but they have also some limitations. They only partly reflect the volume change of final consumption, but it can not fully reflect the changed trend of final consumption structure. In order to distinguish which demands such as consumption, investment and export influence importantly on the departments in the induction, it is necessary for ultimate demand to analyze production induced coefficient and induce inter-dependency ${ }^{[4]}$.

According to the equation $X=(I-A)^{-1} Y$, a row of number respectively in matrix (I-A) $)^{-1}$ multiplied by the ultimate demand column vectors including investment column vectors, consumption and export column vectors makes the ultimate demand induced output.

$$
X_{i}^{s}=\sum_{k=1}^{n} C_{i k} Y_{k}^{s}(i=1,2, \mathrm{~L}, n ; s=1,2,3)
$$

$X_{i}^{s}$ means the ith industry's the ultimate demand based on the item sth; $\mathrm{C}_{\mathrm{ik}}$ says the elements in the matrix $(\mathrm{I}-\mathrm{A})^{-1} ; Y_{k}^{s}$ expresses the ultimate demand value of the ith industry and the item sth; $\mathrm{S}=1,2,3$ represent investment, consumption and export respectively.

The induced output value of the final demand of the ith industry divided by the sum of final demand project can get production induced coefficient. Its calculation formula is shown below.

$$
W_{i}^{s}=\frac{\sum_{k=1}^{n} C_{i k} Y_{k}^{s}}{\sum_{k=1}^{n} Y_{k}^{s}}
$$

$W_{\mathrm{i}}^{s}$ and $\sum_{k=1}^{n} Y_{k}^{s}$ respectively represent production induced coefficient and the sum of final demand project.

The ultimate demand induced output divided by the sum of it is the production induce inter-dependency coefficient, and its calculation formula is shown below.

$$
Z_{i}^{s}=\frac{X_{i}^{s}}{\sum_{s=1}^{3} X_{i}^{s}}(i=1,2, \mathrm{~L}, n)
$$

$Z_{i}^{s}$ represents the inter-dependency coefficient , and $X_{i}^{s}$ represents the induced output with the ith industry and sth ultimate-demand; and $\sum_{s=1}^{3} X_{i}^{s}$ represents the sum of the each ultimate demand induced output of ith industry.

Based on the formula from the above, the paper gives the production induced coefficient and inter-dependency coefficient in china in 2010, which is shown in Table 2 and Table 3.

Table2, Production induced coefficient of departments in 2010

\begin{tabular}{lcccccc}
\hline & $\begin{array}{c}\text { Rural } \\
\text { residents' } \\
\text { consumption } \\
\text { production } \\
\text { induced } \\
\text { coefficient }\end{array}$ & $\begin{array}{c}\text { cosidents } \\
\text { production } \\
\text { induced } \\
\text { coefficient }\end{array}$ & $\begin{array}{c}\text { Government } \\
\text { consumption consumption } \\
\text { production } \\
\text { induced } \\
\text { coefficient }\end{array}$ & $\begin{array}{c}\text { Final } \\
\text { production } \\
\text { induced } \\
\text { coefficient }\end{array}$ & $\begin{array}{c}\text { investment } \\
\text { production } \\
\text { induced } \\
\text { coefficient }\end{array}$ & $\begin{array}{c}\text { Export } \\
\text { production } \\
\text { induced } \\
\text { coefficient }\end{array}$ \\
\hline agriculture & 0.0538 & 0.1079 & 0.0238 & 0.1856 & 0.1608 & 0.0075
\end{tabular}




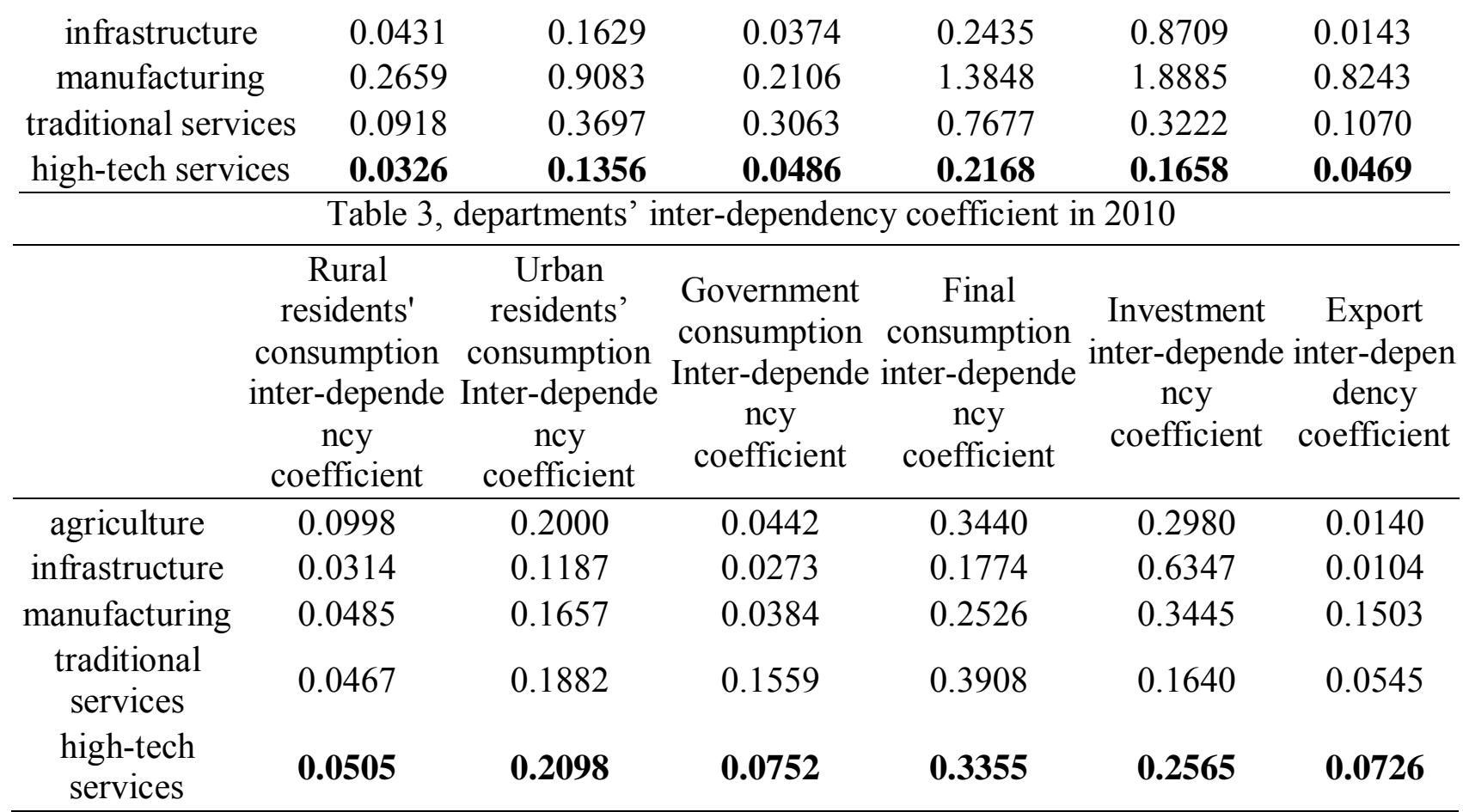

According to the data analysis, the growth of high-technology services output is mainly dependent on the urban residents' consumption in consumption. Because telecommunications, television and the internet have become the indispensable necessities and material basis in People's Daily life, and scientific research and technology projects of government agencies improve the development of scientific research and technical services, so consumption become the most significant final demand among the inducing production effect of high-tech services. Secondly, Followed by investment, the diversification of financial institutions has brought many opportunities and challenges for the investment market,and increased the investment,so it has driven the development of the financial inter-mediation in high-tech services. Finally, export is the minimal inducing production effect

High-tech services, in other words, gets the support of consumption and investment, so both macroeconomic policies have a larger advantage on the development of high-tech services.

The ripple effect of value and price hige-tech services. The industrial correlative research of a industry is reflected that its output and price changes affects other industries from the perspective of macroeconomics.

If output value increases by $\Delta y_{5}$ in high-tech services, other industries' output value will change based on the linkage mechanism of input-output. Variation is as follows:

$$
\left[\begin{array}{l}
\Delta y_{1} \\
\Delta y_{2} \\
\Delta y_{3} \\
\Delta y_{4}
\end{array}\right]=\left[\begin{array}{l}
\bar{b}_{15} \\
\bar{b}_{25} \\
\bar{b}_{35} \\
\bar{b}_{45}
\end{array}\right] \times \frac{\Delta y_{5}}{\bar{b}_{55}}=\left[\begin{array}{l}
0.0610 \\
0.1298 \\
0.7626 \\
0.2578
\end{array}\right] \times \frac{\Delta y_{5}}{1.2074}=\left[\begin{array}{l}
0.0505 \\
0.1075 \\
0.6316 \\
0.2135
\end{array}\right] \times \Delta y_{5}
$$

$\Delta y_{i}(\mathrm{i}=1,2,3,4,5)$ represents respectively output variation of the five departments in the paper.And $\bar{b}_{i j}$ is the column value for high-tech services' the corresponding column in demand matrix completely. The formula indicates that agricultural output value will increase of 0.0505 units, and infrastructure construction 0.1075 units, manufacturing output 0.6316 units, traditional services 0.2135 units based on high-tech services an additional unit. Thus when output value of high-tech services has some changed, manufacturing has the most impact in spread effect, followed by traditional services and infrastructure, but the agricultural changes is the weakest.

According to the Walrasian general equilibrium model that the equilibrium price of any product depends on the level of prices of all kinds of products in the national economy. And the price changes of a sectors' products is bound to cause the price changes of other departments. Assuming that price 
changes of other sectors' products can use the following formula, when price level of high-tech services has changed for some reason.

$$
\left[\begin{array}{l}
\Delta P_{1} \\
\Delta P_{2} \\
\Delta P_{3} \\
\Delta P_{4}
\end{array}\right]=\left[\begin{array}{l}
\bar{b}_{51} \\
\bar{b}_{52} \\
\bar{b}_{53} \\
\bar{b}_{54}
\end{array}\right] \times \frac{\Delta P_{5}}{\bar{b}_{55}}=\left[\begin{array}{l}
0.0753 \\
0.1467 \\
0.1535 \\
0.1289
\end{array}\right] \times \frac{\Delta P_{5}}{1.2074}=\left[\begin{array}{l}
0.0624 \\
0.1215 \\
0.1271 \\
0.1068
\end{array}\right] \times \Delta P_{5}
$$

$\Delta p_{i}(\mathrm{i}=1,2,3,4,5)$ respectively means the price variations of the five departments in the paper, and $\bar{b}_{i j}$ is the row value for high-tech services' the corresponding row in demand matrix completely. As high-tech services has risen in the price level,it can make the price level of agriculture rise 0.0624 units, and infrastructure 0.1215 units ,manufacturing 0.1271 units, traditional services 0.1068 units.Above all, price changes of high-tech services causes the greatest influence on manufacturing and infrastructure, but agriculture is weakest .

\section{Conclusions}

Through input-output analysis on high-tech services, high-tech services has the most pulling effect and the radiation effect to the national economy, following the manufacturing and infrastructure. However, high-tech services influenced on the national economy is not obvious.Secondly, the consumption and investment is the largest influences that cause high-tech services' value growing rapidly. Finally, value and price of manufacturing are affected first, when production value and price change in high-tech services, but agriculture has strong stability with production value and price fluctuation of high-tech services relatively. In summary, high-tech services belongs to the middle industry, which provides more support for the development of the manufacturing and traditional services,so it has a strong linkage effect with manufacturing and infrastructure.

Given this, high-tech services, which is still in early phases of development in china, has many problems, but that it,an emerging industry, has great development space can support the development of other related industries to a certain extent. So government agencies or the relevant enterprise should be nudged to invest heavily and improve policies and regulations on the basis of stable production.On the other hand, they should emphasize support and development of related industries which possess demand pressures and market potential, and ensure moderate and healthy development of it.

\section{Acknowledgments}

This work is supported by The Plan Projects of Science and Technology Hall of Hebei Province:A research on super-local innovation network construction under the background of the industry transferring in Beijing,Tianjin and Hebei(NO.:15457645D);Humanities and Social science research Project of colleges and universities in Hebei Province(NO.:SQ131021).

\section{References}

[1] Dongdong Zhou, Donglin Han, Yongfei Du. Forum on Science and Technology in China,2013,11:5-10.(In Chinese)

[2] Information on http://www.iochina.org.cn/Download/xgxz.html

[3] Rongmei Xiang. Input-output Analysis[M]. Chengdu: Southwestern University of Finance and Economics Press, 2007.07.(In Chinese)

[4] Yunlin Wang, Yun Fu, Ding Li. Journal of Industrial Technological Economics,2008,27 (5).(In Chinese) 